\title{
Type I Human T Cell Leukemia Virus Tax Protein Transforms Rat Fibroblasts through the Cyclic Adenosine Monophosphate Response Element Binding Protein/Activating Transcription Factor Pathway
}

\author{
Matthew R. Smith and Warner C. Greene \\ Howard Hughes Medical Institute, Department of Medicine and Department of Microbiology and Immunology, \\ Duke University Medical Center, Durham, North Carolina 27710
}

\begin{abstract}
The Tax oncoprotein of the type I human $T$ cell leukemia virus (HTLV-I) activates transcription of cellular and viral genes through at least two different transcription factor pathways. Tax activates transcription of the c-fos proto-oncogene by a mechanism that appears to involve members of the cAMP response element binding protein (CREB) and activating transcription factor (ATF) family of DNA-binding proteins. Tax also induces the nuclear expression of the NF- $\mathrm{BB}$ family of rel oncogene-related enhancer-binding proteins. We have investigated the potential role of these CREB/ATF and NF- $\kappa$ B/Rel transcription factors in Tax-mediated transformation by analyzing the oncogenic potential of Tax mutants that functionally segregate these two pathways of transactivation. Rat fibroblasts (Rat2) stably expressing either the wild-type Tax protein or a Tax mutant selectively deficient in the ability to induce NF- $\kappa$ B/Rel demonstrated marked changes in morphology and growth characteristics including the ability to form tumors in athymic mice. In contrast, Rat 2 cells stably expressing a Tax mutant selectively deficient in the ability to activate transcription through CREB/ATF demonstrated no detectable changes in morphology or growth characteristics. These results suggest that transcriptional activation through the CREB/ATF pathway may play an important role in Tax-mediated cellular transformation. (J. Clin. Invest. 1991. 88:1038-1042.) Key words: adult $\mathbf{T}$ cell leukemia/lymphoma $\bullet \mathbf{N F}-\kappa \mathrm{B}, \mathrm{Rel} \cdot$ enhancer-binding proteins $\bullet$ transcription
\end{abstract}

\section{Introduction}

HTLV-I is the etiologic agent of the adult T cell leukemia/lymphoma $(\operatorname{ATLL})^{1}(1,2)$, an often aggressive and fatal malig-

Address correspondence and reprint requests to Dr. Warner C. Greene, Howard Hughes Medical Institute, Department of Medicine, Box 3037, Duke University Medical, Durham, NC 27710. 1991.

Received for publication 8 April 1991 and in revised form 29 May

1. Abbreviations used in this paper: ATF, activating transcription factor; ATLL, adult T cell leukemia/lymphoma; CRE, cAMP response element; CREB, CRE-binding protein; HTLV-I, type I human T cell leukemia virus; LTR, long terminal repeat; neo $^{\mathbf{R}}$, neomycin resistance gene.

J. Clin. Invest.

(c) The American Society for Clinical Investigation, Inc. 0021-9738/91/09/1038/05 $\$ 2.00$

Volume 88, September 1991, 1038-1042 nancy of mature CD4+ T-lymphocytes. The mechanism of type I human T cell leukemia virus (HTLV-I)-induced cellular transformation appears distinct from that of most other transforming animal retroviruses. The HTLV-I genome neither contains a known oncogene (3) nor does this retrovirus promote cis-activation of endogenous proto-oncogenes by sitespecific integration (4). Rather, several lines of evidence suggest that the 40-kD Tax transactivator encoded by the $\mathrm{pX}$ region of HTLV-I plays a central role in cellular transformation. Specifically, mice expressing tax as a transgene develop mesenchymal tumors and neurofibromas $(5,6)$. Further, overexpression of the tax gene in established mouse or rat fibroblast cell lines results in the transformation of these cells (7). Similarly, coexpression of the tax gene with the ras oncogene immortalizes primary rat fibroblasts (8).

Tax is essential for viral replication and potently activates transcription of HTLV-I genes $(9,10)$. In addition, Tax transcriptionally activates several cellular genes involved in $\mathrm{T}$ cell growth, including IL-2, the alpha chain of the IL-2 receptor (IL-2R $\alpha$ ) and the c-fos proto-oncogene (11-14). Tax does not directly bind to the transcriptional regulatory elements within these genes but, rather, acts indirectly through at least two host transcription factor pathways. Tax activation of HTLV-I gene expression involves three imperfectly repeated 21 base enhancer elements present within the proviral long terminal repeat (LTR) (15-17). Tax transactivation of the LTR is mediated through constitutively-expressed cellular proteins that bind to a cAMP response element (CRE) present within these 21-base pair enhancer elements (18). Molecular cloning of cDNAs encoding these enhancer-binding proteins has revealed that they represent members of the CRE-binding protein (CREB) and activating transcription factor (ATF) family of DNA-binding proteins $(19,20)$. The Tax-responsive sequences in the c-fos promoter also contain a CRE (14), suggesting that Tax activation of both the HTLV-I LTR and c-fos promoter may involve the CREB/ATF transcription factors. In contrast, Tax activation of the IL-2 and IL-2R $\alpha$ cellular genes is mediated in part through the induced nuclear expression of NF- $\kappa$ B (21). NF- $\kappa$ B binding activity has recently been shown to correspond to a family of transcription factors that share amino terminal sequence homology with the v-rel oncogene (22-24). This acutely transforming gene product was first identified in the avian reticuloendotheliosis virus strain T (REV-T), which produces rapidly fatal lymphoid tumors in young birds. The activity of NF- $\mathrm{B} / \mathrm{Rel}$ proteins is regulated by a posttranslational mechanism involving their induced release from a cytoplasmic inhibitor termed $I_{\kappa} \mathrm{B}$. Additionally, recent studies have shown that Tax activates these transcription factors at a pre- 
translational level by increasing NF- $\kappa$ B and c-rel mRNA expression (Arima, N., J. A. Molitor, M. R. Smith, J. H. Kim, Y. Daitoku, and W. C. Greene, submitted for publication).

The precise role for Tax-mediated transactivation of either the CREB/ATF or NF- $\kappa$ B/Rel transcription factor pathways in Tax-mediated cellular transformation remains undefined. However, we have recently identified mutant versions of the tax gene that functionally segregate these two pathways of transactivation in Jurkat T cells (25). Specifically, the M22 Tax mutant $\left({ }^{137}\right.$ GlyLeu $\rightarrow$ AlaSer) lacks the ability to induce NF$\kappa \mathrm{B} /$ Rel but retains the ability to transactivate the CRE-dependent HTLV-I LTR and c-fos promoter. Conversely, the M47 Tax mutant $\left({ }^{319}\right.$ LeuLeu $\rightarrow$ ArgSer $)$ lacks the ability to transactivate CRE-dependent promoters but retains the ability to induce NF- $\kappa \mathrm{B} / \mathrm{Rel}$. In this report, we have investigated the oncogenic potential of these phenotypically novel tax mutants when stably introduced into the Rat 2 fibroblast cell line. Both the wild-type and M22 mutant Tax proteins produce marked changes in the morphology and growth characteristics of these cells including anchorage-independent growth and formation of tumors in athymic mice. In contrast, rat fibroblasts expressing the M47 Tax mutant appear phenotypically normal and fail to form tumors in athymic mice. These results suggest that activation of the CREB/ATF transcription factor pathway may play a dominant role in Tax-mediated transformation of fibroblasts.

\section{Methods}

Plasmids. The pcTaxWT-neo plasmid constitutively expresses both the HTLV-I tax gene and the selectable bacterial neomycin resistance gene $\left(\right.$ neo $^{R}$ ) (Fig. 1). An EcoR I/EcoR I fragment containing neo ${ }^{R}$ under the control of the SV40 early promoter was derived from the pSV2-neo plasmid (26) using the polymerase chain reaction (27). The pcTaxWT-neo expression vector was constructed by ligating this fragment into the unique EcoR I site within the pcTax plasmid (25). The pcTaxM22-neo and pcTaxM47-neo mutant expression vectors were subsequently constructed by ligating Sac I/Bst EII fragments from the pcTaxM22 and pcTaxM47 expression vectors (25) into the Sac I/Bst EII backbone of pcTax-neo. The M22 mutation involves the substitution of the dipeptide alanine-serine for amino acids $137-138\left({ }^{137} \mathrm{Gly}\right.$ Leu $\rightarrow$ AlaSer) and creates a unique Nhe I restriction site within the tax gene. The M47 mutation substitutes the dipeptide arginine-serine for amino acids 319-320 $\left({ }^{319}\right.$ LeuLeu $\rightarrow$ ArgSer $)$ and creates a unique Bgl II restriction site within the tax gene.

Preparation of Rat 2 cells stably expressing Tax. The Rat 2 cell line (cell repository line 1764; American Type Culture Collection, Bethesda, MD), a phenotypically normal subclone of the Fischer rat fibroblast cell line Rat-1 (28), was maintained in Iscove's medium supplemented with $5 \%$ heat-inactivated fetal calf serum (complete medium). The pSV2-neo, pcTaxWT-neo, pcTaxM22-neo, and pcTaxM47-neo expression vectors were introduced into Rat 2 cells by calcium phosphate transfection as previously described (29). Transfected cells were cultured for $2 \mathrm{~d}$ in complete medium then simultaneously selected and cloned by seeding various dilutions of cells into individual microtiter wells $(\sim 1000,300,100$, and 30 cells/well $)$ in complete medium containing the $\mathrm{G} 418$ antibiotic $(800 \mu \mathrm{g} / \mathrm{ml})$. After $21 \mathrm{~d}$ of culture, multiple G418-resistant clones were expanded and screened for Tax expression by immunoprecipitation with rabbit anti-Tax antisera. Clones expressing high levels of Tax were selected for further study and maintained in complete media containing G418 $(200 \mu \mathrm{g} / \mathrm{ml})$.

Immunoprecipitation. Subconfluent cell cultures $\left(\sim 10^{6}\right.$ cells $)$ were metabolically labeled for $4 \mathrm{~h}$ with $\left[{ }^{35} \mathrm{~S}\right]$ cysteine $(200 \mu \mathrm{Ci} / \mathrm{ml})$ and extracted in RIPA buffer as previously described (25). Cell extracts were precleared with preimmune rabbit antisera then specifically immuno-

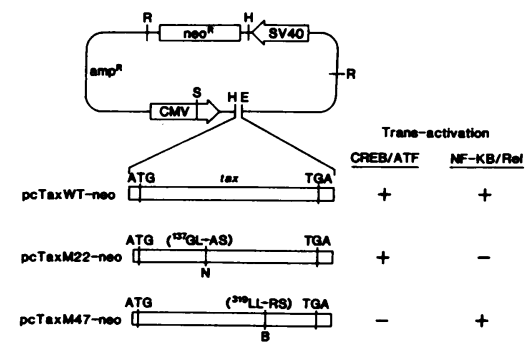

Figure 1. Summary of transcriptional phenotypes of the HTLV-I tax gene mutants. The wildtype Tax protein activates transcription of various viral and cellular genes through both the NF- $\kappa$ B Rel and CREB/ATF cellular transcription factor

pathways. In contrast, the M22 and M47 tax gene mutants demonstrate differential phenotypes of transactivation (25). The M22 tax mutant $\left({ }^{137}\right.$ GlyLeu $\rightarrow$ AlaSer) fails to activate NF- $\kappa$ B-responsive promoters but retains the ability to activate CREB/ATF responsive promoters $(-,<5 \%$ wild-type activity;,$+>50 \%$ wild-type activity). Conversely, the M47 tax mutant $\left({ }^{319}\right.$ LeuLeu $\rightarrow$ ArgSer) fails to activate transcription of CREB/ATF-responsive promoters but retains the ability to activate NF- $\kappa$ B-responsive promoters. The pcTax-neo plasmid expresses the HTLV-I tax gene under the control of the human cytomegalovirus immediate early promoter (CMV) and the selectable bacterial neo ${ }^{R}$ under the control of the SV40 early promoter (SV40). Relevant restriction sites are designated by the following one letter abbreviations: $B, \mathrm{Bg} 1 \mathrm{II} ; E$, Bst EII; $H$, Hind III; $N$, Nhe I; $R$, Eco R1; and $S$, Sac I.

precipitated with rabbit anti-peptide antisera specific for the carboxy terminal 33 amino acids of Tax ( $\alpha$ Tax-C; 1:200 dilution). The resultant immunoprecipitates were analyzed on discontinuous SDS-10\% polyacrylamide gels electrophoresed under reducing conditions.

In vitro growth in soft agar and in vivo tumorigenicity in nude mice. The ability of the stably transfected Rat 2 cell lines to form colonies in semisolid media was assayed by culturing $2 \times 10^{3}$ cells per $35-\mathrm{mm}$ dish in complete media containing $0.33 \%$ agarose and $200 \mu \mathrm{g} / \mathrm{ml} \mathrm{G} 418$. After $21 \mathrm{~d}$ of culture, cell lines that grew as colonies of greater than 100 cells were scored as positive. In vivo tumorigenicity was assessed by subcutaneous injection of $2.5 \times 10^{6}$ viable cells into 4-7-wk-old female athymic BALB/c mice (Life Sciences, St. Petersburg, FL). Tumor development was monitored at regular intervals. Tumor tissue was analyzed for Tax expression by Western blot analysis as previously described (25).

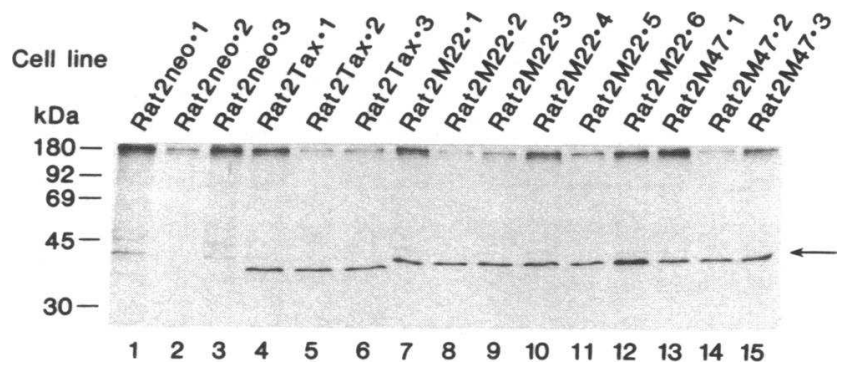

Figure 2. Immunoprecipitation analysis of Tax expression in stably transfected clones of Rat 2 cells. Subconfluent cultures of Rat 2 clones stably transfected with either pSV2-neo (lanes 1-3), pcTaxWT-neo (lanes 4-6), pcTaxM22-neo (lanes 7-12), or pcTaxM47-neo (lanes 13-15) were metabolically radiolabeled with $\left[{ }^{35} \mathrm{~S}\right]$ cysteine for $4 \mathrm{~h}$ followed by extraction in RIPA buffer. These cellular extracts were precleared with preimmune rabbit antisera then specifically immunoprecipitated rabbit anti-peptide antisera directed against the carboxy terminus of the Tax protein ( $\alpha$ Tax-C). Immunoprecipitates were analyzed on SDS-10\% polyacrylamide gels and visualized by autoradiography. The migration of known molecular weight standards is indicated at the left and the position of the $40-\mathrm{kD}$ Tax protein is indicated by the arrow. 

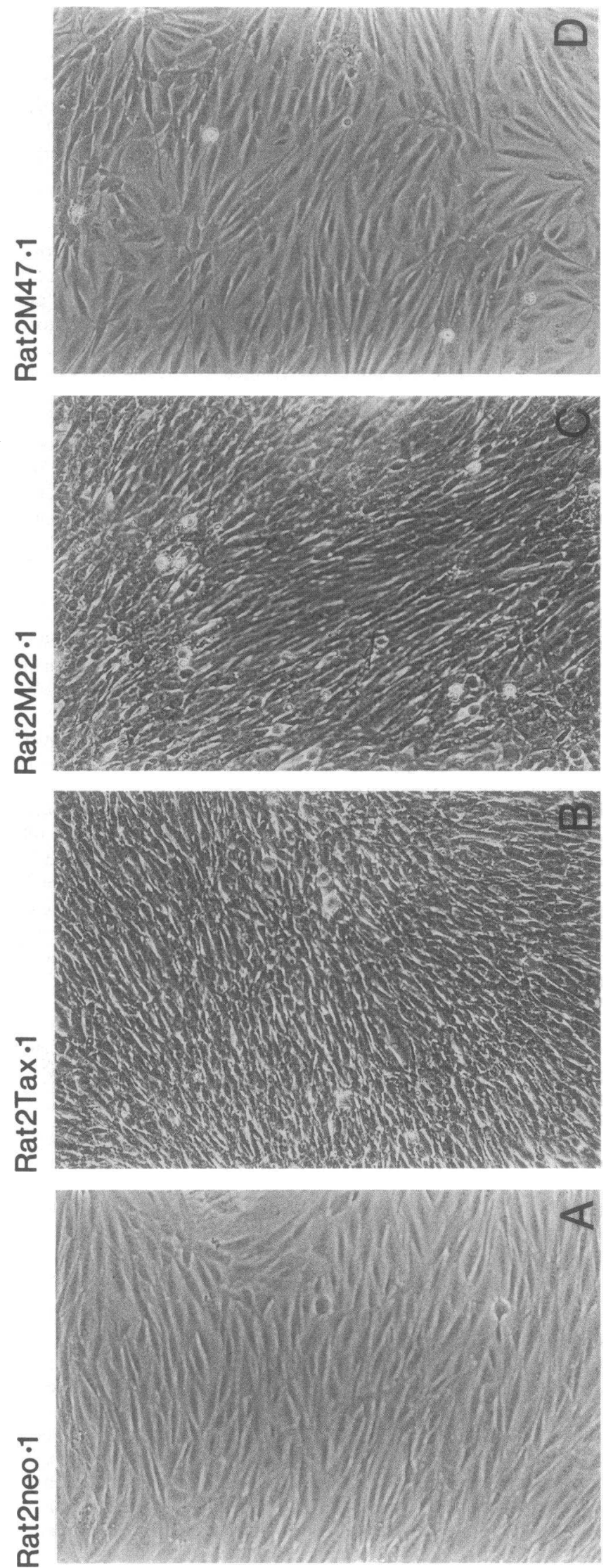

\section{Results}

To investigate the potential role of the NF- $\kappa$ B/Rel and CREB/ ATF transcription factor pathways in Tax-mediated cellular transformation, the growth characteristics and tumorigenicity of rat fibroblast cells constitutively expressing high levels of the wild-type or select mutant Tax proteins were examined. The pSV2-neo, pcTaxWT-neo, pcTaxM22-neo, and pcTaxM47neo plasmids (Fig. 1) were introduced into Rat 2 cells by calcium phosphate-mediated DNA transfection. Transfected cells were then selected with the antibiotic G418 and cloned by limiting dilution. Tax expression in each of the resultant G418-resistant Rat 2 clones was analyzed by immunoprecipitation using rabbit anti-peptide antisera directed against the carboxy terminus of the Tax protein. Approximately $30 \%$ of the G418resistant clones expressed detectable amounts of Tax protein in this assay. Clones expressing high levels of the wild-type and mutant Tax proteins were selected for further analysis (Fig. 2). The presence of the appropriate plasmid DNA was verified in each of these clones by Southern blot analyses (data not shown). To confirm the functional phenotypes of these novel mutants in Rat 2 cells, cell lines expressing either the M22 or M47 mutant Tax protein were transfected with CRE-dependent and $\kappa \mathrm{B}$-dependent chloramphenicol acetyl transferase (CAT) reporter plasmids. Consistent with the previously reported phenotype of these mutants in transiently transfected Jurkat $T$ cells (25), Rat 2 cells stably expressing the M22 mutant preferentially activate CRE-dependent promoters, whereas Rat 2 cells stably expressing the M47 mutant preferentially activate $\kappa \mathrm{B}$-dependent promoters (data not shown). In contrast, Rat 2 cells stably expressing the wild-type Tax protein activate CRE-dependent and $\kappa \mathrm{B}$-dependent promoter with similar efficiency compared with cell lines expressing these mutant proteins.

Morphology. Rat 2 cell lines stably expressing only the $\mathbf{n e o}^{\mathbf{R}}$ gene grow as uniform monolayers of cells that undergo contact inhibition at confluence (Fig. $3 A$ ). The morphology and growth characteristics of Rat 2 cell lines stably expressing the M47 Tax mutant are indistinguishable from that of the Rat2neo cell lines (Fig. 3 D). In contrast, Rat 2 cells stably expressing either the wild-type or M22 mutant Tax protein grow as an irregular and densely packed sheet of cells (Fig. 3, $B$ and C). These cells do not undergo contact inhibition at confluence, forming both microscopic and macroscopic foci after 7 to $14 \mathrm{~d}$ in culture.

In vitro growth in soft agar. To assess potential differences in the requirement of cell anchorage for growth, each of the Tax-expressing Rat 2 clones were cultured in semisolid media. Rat 2 cells expressing either the wild-type or M22 mutant Tax protein formed small colonies in soft agar within $7 \mathrm{~d}$ of culture. These colonies continued to grow and reached macroscopic size ( $>100$ cells/colony) after 3 wk of culture (Table I, and data not shown). Rat 2 cells expressing the M47 Tax mutant or neo ${ }^{R}$ gene alone also formed small colonies ( $\sim 10$ cells/colony) in soft agar after $\sim 7 \mathrm{~d}$ in culture. However, these small colonies failed to increase in size even after 3 wk in culture (Table $I$, and data not shown).

Figure 3. Phase contrast photomicrographs (magnification, 100), of wild-type and mutant Tax-expressing Rat 2 cell lines. Representative clones were cultured for $5 \mathrm{~d}$ after plating $1 \times 10^{5}$ cells per 10 -cm dishes. 
In vivo tumorigenicity. After subcutaneous delivery of 2.5 $\times 10^{6}$ viable cells into 4-7-wk-old athymic BALB/c mice, all three of the wild-type Tax-expressing cell lines and all six of the M22 mutant Tax-expressing lines produced visible tumors at the site of injection within 7-10 d (Table I). These tumors continued to enlarge, reaching 4 to $12 \mathrm{~mm}$ within $3 \mathrm{wk}$. Tax protein expression was detectable within these tumors as assessed by Western blot analysis (data not shown). In sharp contrast, both the M47 mutant Tax-expressing cell lines and neo ${ }^{R}$ expressing control Rat 2 cells did not form detectable tumors during the same period of observation (Table I).

\section{Discussion}

The HTLV-I Tax oncoprotein is a pleiotropic transcriptional activator. Tax activates a variety of genes containing functional $\kappa \mathrm{B}$ enhancer elements by inducing the nuclear expression of the NF- $\kappa$ B/Rel family of enhancer-binding proteins (22-24). Tax also activates the c-fos proto-oncogene by a mechanism that appears to involve the CREB/ATF family of transcription factors $(14,25)$. We have recently identified and characterized $\operatorname{tax}$ gene mutants that functionally segregate activation of the $\mathrm{NF}-\kappa \mathrm{B} / \mathrm{Rel}$ and CREB/ATF transcription factor pathways (25). In this study, we have investigated the role of these pathways in Tax-mediated transformation of nonlymphoid rat fibroblasts. Consistent with earlier reports (7), Rat 2 cells stably expressing the wild-type Tax protein displayed marked changes in morphology and growth characteristics including anchorage-independent growth and formation of tumors in athymic mice. Rat 2 cells stably expressing the M22 Tax mutant, which

Table 1. Oncogenic Potentials of Tax-expressing Rat2 Cell Lines

\begin{tabular}{cccc}
\hline Cell Line & $\begin{array}{c}\text { Growth in } \\
\text { soft agar }\end{array}$ & $\begin{array}{c}\text { In vivo } \\
\text { tumorigenicity }\end{array}$ & $\begin{array}{c}\text { Average tumor } \\
\text { diameter }\end{array}$ \\
\hline Rat2neo.1 & & & $m m$ \\
Rat2neo.2 & - & $0 / 3$ & - \\
Rat2neo.3 & - & $0 / 3$ & - \\
Rat2Tax.1 & + & $0 / 3$ & - \\
Rat2Tax.2 & + & $3 / 3$ & 9.7 \\
Rat2Tax.3 & + & $3 / 3$ & 5.4 \\
Rat2M22.1 & + & $3 / 3$ & 5.0 \\
Rat2M22.2 & + & $3 / 3$ & 4.4 \\
Rat2M22.3 & + & $4 / 4$ & 6.3 \\
Rat2M22.4 & + & $3 / 3$ & 5.1 \\
Rat2M22.5 & + & $3 / 3$ & 6.3 \\
Rat2M22.6 & + & $3 / 3$ & 5.4 \\
Rat2M47.1 & - & $3 / 3$ & 4.4 \\
Rat2M47.2 & - & $0 / 3$ & - \\
Rat2M47.3 & - & $0 / 3$ & - \\
& & $0 / 3$ & - \\
\hline
\end{tabular}

* Anchorage-independent growth of the various Tax-expressing and control cell lines was determined by culturing cells in semisolid media ( $0.33 \%$ agarose) for $3 \mathrm{wk}$. Cell lines that formed large colonies $(>100$ cells) after $3 \mathrm{wk}$ in culture were scored as positive $(+)$.

${ }^{\ddagger}$ In vivo tumorigenicity was determined by subcutaneous injection of $2.5 \times 10^{6}$ viable cells into 4-7 wk old athymic BALB/c mice. Data are expressed as number of mice with detectable tumors $3 \mathrm{wk}$ after injection/number of mice injected. The diameter of each tumor was measured 3 wk postinjection. lacks the ability to induce NF- $\kappa \mathrm{B} /$ Rel but retains the ability to activate transcription through CREB/ATF, produced a similar transformed phenotype both in vitro and in vivo. In contrast, Rat 2 cells stably expressing the M47 Tax mutant, which lacks the ability to activate transcription through CREB/ATF but retains the capacity to induce NF- $\mathrm{B} / \mathrm{Rel}$, displayed no detectable changes in morphology or growth characteristics. These results suggest that Tax transactivation through the CREB/ ATF pathway plays a central role in Tax-mediated transformation of fibroblasts. Tax transactivation of the c-fos proto-oncogene likely participates in this transformation process because the overexpression of Fos protein also leads to the transformation of rat and mouse fibroblasts (30). However, our findings do not exclude the contribution of other CREB/ATF-responsive genes to this transformation process.

Tax induces the expression of NF- $\kappa \mathrm{B} /$ Rel in lymphoid and some nonlymphoid cells including Rat2 fibroblasts (31-33, and P. Sista, M. R. Smith, and W. C. Greene, unpublished observations). However, the ability of the M22 Tax mutant, but not M47 Tax mutant, to transform Rat 2 cells suggests that the induction of NF- $\kappa \mathrm{B}$ is neither necessary nor sufficient to transform these cells. In contrast, Tax activation of NF- $\kappa B /$ Rel likely participates in the transformation of T-lymphocytes, because Tax transactivation of the genes for both IL-2 and the $\alpha$ chain of the IL-2 receptor requires induction of NF- $\kappa B /$ Rel (21). These differences may have important implications for understanding ATLL.

The development of ATLL appears to represent a multistep process (34). Early HTLV-I infection is likely characterized by a period of polyclonal $\mathrm{T}$ cell proliferation (35). The ability of Tax to transactivate the genes encoding IL- 2 and IL-2R $\alpha$ raises the possibility that this viral transactivator may initiate the process of leukemogenesis by promoting a period of autocrine $T$ cell growth. The long period of clinical latency that precedes the development of leukemia (36), and the observation that leukemic cells from ATLL patients are monoclonal (2), suggest that additional cellular events are required for the development of the full malignant phenotype (34). The nature of these later cellular events remains undefined. However, the ability of Tax to transform nonlymphoid cells by a mechanism that is distinct from its ability to induce NF- $\kappa \mathrm{B} / \mathrm{Rel}$ raises the intriguing possibility that one or more of these additional events may also be mediated by Tax. Thus, Tax may initiate the process of leukemogenesis by activating the NF- $\kappa \mathrm{B} /$ Rel pathway and induce subsequent steps in the transformation process by activating additional cellular genes through CREB/ATF. A more complete understanding of the role of Tax and other viral gene products in the progression to ATLL will require the development of an appropriate animal model of this disease.

\section{Acknowledgments}

We thank Hal Bogerd and Gary Huckaby for assistance with in vivo tumorigenicity studies and Ms. Bonnie Kissell for secretarial assistance.

M. R. Smith is supported by the Medical Scientist Training Program.

\section{References}

1. Poiesz, B. F., F. W. Ruscetti, A. F. Gazdar, P. A. Bunn, J. D. Minna, and R. C. Gallo. 1980. Detection and isolation of type C retrovirus particles from fresh cultured lymphocytes of a patient with cutaneous T-cell lymphoma. Proc. Natl. Acad. Sci. USA. 77:7415-7419. 
2. Yoshida, M., I. Miyoshi, and Y. Hinuma. 1982. Isolation and characterization of retrovirus from cell lines of human adult T-cell leukemia and its implication in the disease. Proc. Natl. Acad. Sci. USA. 79:2031-2035.

3. Seiki, M., S. Hattori, and M. Yoshida. 1982. Human adult T-cell leukemia virus: molecular cloning of the provirus DNA and the unique terminal structure. Proc. Natl. Acad. Sci. USA. 79:6899-6902.

4. Seiki, M., R. Eddy, T. B. Shows, and M. Yoshida. 1984. Nonspecific integration of the HTLV provirus genome into adult T-cell leukemia cells. Nature (Lond.). 309:640-642.

5. Nerenberg, M., S. H. Hinrichs, R. K. Reynolds, G. Khoury, and G. Jay. 1987. The tat gene of human T-lymphotropic virus type I induces mesenchymal tumors in transgenic mice. Science (Wash. DC). 237:1324-1329.

6. Hinrichs, S. H., M. Nerenberg, R. K. Reynolds, G. Khoury, and G. Jay. 1987. A transgenic mouse model for human neurofibromatosis. Science (Wash DC). 237:1340-1343.

7. Tanaka, A., C. Takahashi, S. Yamaoka, T. Nosaka, M. Maki, and M Hatanaka. 1990. Oncogenic transformation by the tax gene of human T-cell leukemia virus type I in vitro. Proc. Natl. Acad. Sci. USA. 87:1071-1075.

8. Pozzatti, R., J. Vogel, and G. Jay. 1990. The human T-lymphotropic virus type I tax gene can cooperate with the ras oncogene to induce neoplastic transformation of cells. Mol. Cell. Biol. 10:413-417.

9. Chen, I. S. Y., D. J. Slamon, J. D. Rosenblatt, N. P. Shah, S. G. Quan, and W. Wachsman. 1985. The $\mathrm{x}$ gene is essential for HTLV replication. Science (Wash. DC). 229:54-58.

10. Sodroski, J., C. Rosen, W. C. Goh, and W. Haseltine. 1985. A transcriptional activator protein encoded by the $\mathrm{x}$-lor region of the human $\mathrm{T}$-cell leukemia virus. Science (Wash. DC). 228:1430-1434.

11. Inoue, J., M. Seiki, T. Taniguchi, S. Tsuru, and M. Yoshida. 1986. Induction of interleukin- 2 receptor gene expression by $\mathrm{p} 40^{\mathrm{x}}$ encoded by human T-cell leukemia virus type I. EMBO (Eur. Mol. Biol. Organ.) J. 5:2883-2888.

12. Cross, S. L., M. B. Feinberg, J. B. Wolf, N. J. Holbrook, F. Wong-Staal, and W. J. Leonard. 1987. Regulation of the human interleukin-2 receptor $\alpha$ chain promoter: activation of a nonfunctional promoter by the transactivator gene of HTLV-I. Cell. 49:47-56.

13. Siekevitz, M., M. B. Feinberg, N. Holbrook, F. Wong-Staal, and W. C. Greene. 1987. Activation of interleukin 2 and interleukin 2 receptor (Tac) promoter expression by the transactivator (tat) gene product of human T-cell leukemia virus, type I. Proc. Natl. Acad. Sci. USA. 84:5389-5393.

14. Fujii, M., P. Sassone-Corsi, and I. M. Verma. 1988. c-fos promoter transactivation by the tax protein of human T-cell leukemia virus type I. Proc. Natl. Acad. Sci. USA. 85:8526-8530.

15. Paskalis, H., B. K. Felber, and G. N. Pavlakis. 1986. Cis-acting sequences responsible for the transcriptional activation of human T-cell leukemia virus type I constitute a conditional enhancer. Proc. Natl. Acad. Sci. USA. 83:6558-6562.

16. Shimotohno, K., M. Takano, T. Terunchi, and M. Miwa. 1986. Requirements of multiple copies of a 21 -nucleotide sequence in the $U 3$ region of human T-cell leukemia virus type I and type II long terminal repeats for trans-acting activation of transcription. Proc. Natl. Acad. Sci. USA. 83:8112-8116.

17. Brady, J., K.-T. Jeang, J. Duvall, and G. Khoury. 1987. Identification of p40 ${ }^{x}$-responsive regulatory sequences within the HTLV-ILTR. J. Virol. 61:21752181.

18. Jeang, K.-T., I. Boros, J. Brady, M. Radonovich, and G. Khoury. 1988. Characterization of cellular factors that interact with the human T-cell leukemia virus type I p40x-responsive 21-base-pair sequence. $J$. Virol. 62:4499-4509.

19. Yoshimura, T., J. Fujisawa, and M. Yoshida. 1990. Multiple cDNA clones encoding nuclear proteins that bind to the tax-dependent enhancer of
HTLV-I: all contain a leucine zipper structure and basic amino acid domain. EMBO (Eur. Mol. Biol. Organ.) J. 9:2537-2542.

20. Tsujimoto, A., H. Nyunoya, T. Morita, T. Sato, and K. Shimotohno 1991. Isolation of CDNAs for DNA-binding proteins which specifically bind to a tax responsive enhancer element in the long terminal repeat of human T-cell leukemia virus type I. J. Virol. 65:1420-1426.

21. Lenardo, M. J., and D. Baltimore. 1989. NF- $\kappa$ B: a pleiotropic mediator of inducible and tissue-specific gene control. Cell. 58:227-229.

22. Ghosh, S., A. M. Gifford, L. R. Riviere, P. Tempst, G. P. Nolan, and D. Baltimore. 1990. Cloning of the p50 DNA binding subunit of NF-кB: homology to rel and dorsal. Cell. 62:1019-1029.

23. Kieran, M., V. Blank, F. Logeat, J. Vandekerckhove, F. Lottspeich, O. Le Bail, M. B. Urban, P. A. Baeuerle, and A. Israël. 1990. The DNA binding subunit of NF- $\mathrm{KB}$ is identical to factor $\mathrm{KBF} 1$ and homologous to the rel oncogene product. Cell. 62:1007-1018.

24. Ballard, D. W., W. Walker, S. Doerre, P. Sista, J. A. Molitor, E. P. Dixon, N. J. Peffer, M. Hannink, and W. C. Greene. 1990. The v-rel oncogene encodes a $\kappa \mathrm{B}$ enhancer binding protein that inhibits NF- $\kappa \mathrm{B}$ function. Cell. 63:803-814.

25. Smith, M. R., and W. C. Greene. 1990. Identification of HTLV-I tax trans-activator mutants exhibiting novel transcriptional phenotypes. Genes \& Dev. 4:1875-1885.

26. Southern, P. J., and P. Berg. 1982. Transformation of mammalian cells to antibiotic resistance with a bacterial gene under the control of the SV40 early promoter. J. Mol. Appl. Genet. 1:327-41.

27. Coen, D. M. 1990 . Enzymatic amplification of DNA by the polymerase chain reaction: standard procedures and optimization. In Current Protocols in Molecular Biology F. M. Ausubel, R. Brent, R. E. Kingston, D. D. Moore, J. G. Seidman, J. A. Smith, and K. Struhl, editors. John Wiley \& Sons, Inc., New York. Vol. 2:15.1.

28. Topp, W. C. 1981. Normal rat cell lines deficient in nuclear thymidine kinase. Virology. 113:408-411.

29. Kingston, R. E. 1988. Introduction of DNA into eukaryotic cells: calcium phosphate transfection. In Current Protocols in Molecular Biology F. M. Ausubel, R. Brent, R. E. Kingston, D. D. Moore, J. G. Seidman, J. A. Smith, and K. Struhl, editors. John Wiley \& Sons, Inc., New York. Vol. 1:9.1.

30. Miller, A. D., T. Curran, and I. M. Verma. 1984. c-fos protein can induce cellular transformation: a novel mechanism of activation of a cellular oncogene. Cell. 36:51-60.

31. Leung, K., and G. J. Nabel. 1988. HTLV-I transactivator induces interleukin-2 receptor expression through an NF-кB like factor. Nature (Lond.) 333:776-778.

32. Ballard, D. W., E. Böhnlein, J. W. Lowenthal, Y. Wano, R. B. Franza, and W. C. Greene. 1988. HTLV-I Tax induces cellular proteins that activate the $\kappa B$ element in the IL-2 receptor- $\alpha$ gene. Science (Wash. DC). 241:1652-1655.

33. Ruben, S. M., H. Poteat, T.-H. Tan, K. Kawakami, R. Roeder, R., W. Haseltine, and C. A. Rosen. 1988. Cellular transcription factors and regulation of IL-2 receptor gene expression by HTLV-I tax gene product. Science (Wash. DC). 241:89-91.

34. Smith, M. R., and W. C. Greene. 1991. Molecular biology of the type human T cell leukemia virus (HTLV-I) and Adult T cell leukemia. J. Clin. Invest. 87:761-766

35. Green, P. L., and I. S. Y. Chen. 1990. Regulation of human T-cell leukemia virus expression. FASEB (Fed. Am. Soc. Exp. Biol.) J. 4:169-175.

36. Kim, J. H., and D. T. Durack. 1988. Manifestations of human T-lymphotropic virus type I infection. Am. J. Med. 84:919-927. 